\title{
Teacher-pupil Relations and Subject Preference
}

\author{
Xiyan $\mathrm{Li}^{*}$
}

\author{
${ }^{1}$ Nan Jing Agriculture University \\ *Corresponding author. Email: 9183011806@njau.edu.cn
}

\begin{abstract}
This study aims to understand how teacher-pupil relations affect pupils' subject preference, and what impacts it might have to pupils' academic attainments. Factors of how teacher-pupil relations come to being are investigated. Pupils are a group of children who are aged 6-12. Their mind and world view have not fully formed yet. When pupils go to school to accept compulsory lessons, they will have their personal preference to the subjects they have learn about. Their preferences are diverse, partially for the discrepancy of personalities. By reviewing former researches and findings, the study explored the effects the relations might bring to individuals growth and school attainments. The importance of relations has been pointed out. In the process of studying, some population characteristics are discovered that they might be involved in when bad relations happen between teachers and pupils. When bad relations or conflicts have risen between pupils and teachers, pupils with different socio-demographic elements have different attitudes towards their teachers. This will also influence pupils' subject preference when bad relations come to being. Relative literatures have been looked up to find out the correlations among them. In a word, subject preference can be affected with the alteration of relations, and it can be related to some population features. This study also illuminates one of the goals of relative researches in the future: researchers should pay attention to the prevention done by teachers to avoid bad relations and the solution of mitigating bad relations when they actually happen between teachers and pupils
\end{abstract}

Keywords: teacher-pupil relations, subject preference, pupil, population characteristics, academic achievements.

\section{INTRODUCTION}

Interaction is natural as human is gregarious. People try to build interpersonal interaction and gain responding and feedback. Heath and Hindmarsh have mentioned that developing routines, strategies, practices and procedures results in social interaction [1]. Individuals living in the contemporary society are having interactions with each other, or giving feedback to lots of stuffs. People feel the pain when they are hurt physically or mentally, share ideas to each other, etc.

Nowadays more and more students go to school for further study and academic acquisitions. They have classes in school, communicate with their teachers about academic difficulties they have. In the past students were afraid of teachers, or supervisors in their school. However, the society is more enlightened than what it was in the past, and teachers make friends with students sometimes.

To make their students comprehend course content, teachers will use multiple teaching methods to interact with their students and obtain real conditions of students' study. Normally teachers will throw questions to the class and waiting for students to give them feedback. Some will create some fun games related to the subjects, or give students relative homework to finish. Diverse interaction with students will make them understand their subjects more deeply. Teachers will adopt new teaching strategies to help with their work. The spirit of innovation has positive impacts on both teachers and students. It has been revealed by Naz and Murad that innovative teaching methods should be implemented and modified to meet the students' need [2].

Pupils are energetic and easy to distract. They lack discerning ability to choose helpful resources and learn autonomously. Teachers find it difficult sometimes to manage the class and control the rhythm of teaching. Thus teachers come up with rules and standards to regulate pupils' behaviors, and also learning strategies appropriate for pupils. For pupils, courses will be much easier to understand, because their knowledge to the world is still not enough. They need to understand more 
to learn more. In addition, their concentration lasts for a short time, and complex knowledge needs them to focus for a long time, which makes pupils hard to understand their subjects thoroughly and clearly. So the textbooks must contain easy knowledge for pupils to understand within their "concentrating time".

Students are made up of persons with varieties of characteristics, which lead to subject preference. Some students prefer science, while some may prefer to art, or music. For instance, the information they have got from the social media or some inspiration of life. Mostly, by having all kinds of courses in all stages of academic requirements, students will eventually understand what areas they are truly interested in, and a class contains many elements. Students have no conscious about subjects when they are on the first day of school. They establish their preference of their subject interest from their teachers, for they spend most of the time per day staying with them.

Although a large quantity of researches discussing about the relationship among teachers and students have been published, there are a few studies talking about whether population characteristics have been involved when bad relations between teachers and pupils come to being, and what impacts it will have on subject preferences of pupils. Furrer and Skinner indicated that some socio-demographic characteristics like gender have become one of factors that influence teacher-pupil relations [3]. Teachers should guide their students to let them learn in a proper way by considering pupils' characteristics when dealing with everything about pupils, which is what a good and qualified teacher should comprehend and exert. It involves not only academic achievements, but also the forming of habits and preferences. High value teachers can bring good impacts on pupils, and more benefits will be brought to pupils' long-run attainments in all aspects [4].

\section{TEACHER-STUDENT RELATIONS}

\subsection{Authoritative teachers and obedient students}

Multiple relations between teachers and pupils can be multiple. It can be teaching process in which teacher and pupils spend most of the school time dealing with studying problems, impart pupils with new knowledge and help them brush up the old ones.

Normally, class routine is fixed: teachers ask pupils questions, wait for their response, assign homework and review in the next day. Chinese and English teachers ask pupils to stand up and read some paragraphs of an article in front of the whole class, or they will dictate some new-learnt words or phrases. There are also some fun games of relative subjects created by teachers, such as idiom solitaire or English sitcom. For Math teachers, they choose to have calculation tests, and they will also select pupils to solve mathematical problems in front of the class. Teachers maximize teaching effects by designing disparate teaching methods.

Teachers express their feelings towards pupils in both verbal and non-verbal ways. When a teacher thinks a student is doing well, she/he might touch her/his head, or greet this student with smiles. As the growing of pupils, their use of nonverbal signals becomes more subtle and sensitive, and so does their understanding of it [5]. In a study provided by S.R. St J. Neill about the effect of teachers' facial expression and posture on children, touch is accepted by all groups of involved children of different ages as a way of teachers showing friendliness. In a word, the teacher will be nice to this student. Behaviors and feelings are mutual. Pupils will also show their affections or rejection. If a student likes her/his teacher, she/he will show respects to the teacher, and also try hard to perform well in this teacher's class to win the favor.

Apart from that, when being in a class in a primary school, there always have different types of pupils. Teachers will give their attention to some pupils who needs extra "care". For instance, pupils have lower grades than others, or they have some physical problems. Teachers have to talk to them to confirm their study conditions. These factors which attach importance to individual differences, children's need and social learning are called "Progressivism" by Kerlinger and Kaya [6]. Or teachers will create different strategies through the characteristics of the whole class, for students' learning result can be sensitively affected by many factors [7], and they do not have enough time and energy to constitute a studying plan for each student. Thus, they need to figure out some proper ways to make their teaching methods fitting into the whole class.

For pupils, they are told by parents that students should respect teachers in school, and go to ask your teacher when you have study problems. When there is something serious happens in school, pupils will first go to teachers' for help. Teacher is more like a leader for pupils, since pupils' parents would not company with them all day.

\subsection{Reasons for teacher-oriented relations}

Teacher-oriented relations have existed for a long time in China. But what are the reasons lead to it? Students' academic achievements can be explained to a large extent. The most significant task for students is to get a good mark in the exam and be admitted to a good school, whether it is a high school or a university. Chasing for academic achievements is one of the most important things in students' life. However, in the process of forming the relations between teachers and pupils, not only teachers should involve but also pupils 
themselves. Helena Marsh had mentioned that the key factor to make students thrive in school is the high level of students' participation [8]. For pupils, they need to finish their homework and pass the exams. For teachers, it is their job to help pupils achieve their academic achievements. The requirement of study forms the relations between teachers and pupils, for most of the time they are dealing with study problems with each other, and it is also the main reason for them to go to school.

When being in a class in a primary school, there always have different types of pupils. Teachers will give their attention to some pupils who needs extra "care". For instance, pupils have lower grades than others, or they have some physical problems. Teachers have to talk to them to confirm their conditions.

Teacher is more like a leader, especially when their parents are not around. When they meet something that is difficult for them to solve, they usually go to the leader for help. Pupils' ability of imitating is very strong. According to Markus Talvio el al. [9], the social and emotion ability might influence pupils in all aspects. Teacher is the model for pupils. By observing adults, pupils decide what are appropriate to imitate. However, the models can both lead to positive and negative effect [10]. If a teacher himself has some bad habits, he might inadvertently reveal them and his bad manners may cause improper mimicry.

\subsection{Significance of relations}

It is noted by K. M. Evans that teachers are the most important and influential adults in pupils' life after their parents, the ones who put enormous impacts in pupils' growth and mind [11]. The exact age of pupils is 6-12, and this is a stage when students are learning not just how to study but how to form a good personality, and also the way of seeing the world. Good teacher-student relations can help pupils grow up more confidently, and a good relationship is good for their mental health. Frances Mathews et al. have pointed out that $13 \%$ of the children and teenagers who have reached the age of accepting compulsory education have mental problems [12]. They also found data in other studies that in many countries, the most common consult service in relation to children's mental health in school is teacher. Obviously mental health disorder is common among children, and teachers play a very important role of leading pupils to the "right path". Pupils are a group of children who are forming their mind and shaping their own opinions. There should be someone who can have a healthy relationship with them to deliver them knowledge of the world.

Anouke Bakx et al. have mentioned that a strong effect can be seen of teachers' behaviors on students' outcome [13]. If teachers treat their students bad or be unfriendly to students, the interest for students of certain subjects will decrease. Student is not the only one who should work hard and pay attention to the process of studying. It is a co-operation between teachers and students. Teachers mobilize their whole passion and motivation to give their students the best they have, and these can inspire pupils' interest and enthusiasm towards studying.

Thus, the relations bring effects to pupils' academic achievement. In a research done by William L. Sander and June C. Rivers, they studied whether teachers will promote pupils' academic attainment when pupils go for further study [14]. They used database in Tennessee's two metropolitans systems to seek out the result. The conclusion had been revealed by formers that teachers' effect is the most single dominant factor of students' grades. The two researchers strongly indicated and confirmed the result, which proves that teachers have things to do with pupils' academic achievement. Their research suggested that students should be given to effective teachers instead of the ineffective, which can improve students' grades, which will bring healthy relations between teachers and pupils on academic stuff. Good teachers are in the "lucky- of-the-draw" of teachers' sequence, and the sequence play the most significant role in pupils' life. That means effective teachers who have good relations with pupils have positive impacts on pupils' grades. However, if pupils are not lucky enough, they will meet bad teachers and their grades will get "hurt" by teachers' ineffectiveness. What a teacher is like can really influence pupils' marks, so it is significant that teacher-pupil relations should exist in a healthy way.

\section{SUBJECT PREFERENCE}

\subsection{Factors causing subject preference}

Pupils will face their subject preference when they start having classes in school. Apeh et al. pointed out that psychologists are interested in personal difference because it links to an individual's personality, learning and personal motivation, which means choices of individuals are related to the diversity of human beings [15]. By analyzing the scores of different types of pupils, they drew out a conclusion that diverse personalities cause the existence of subject preference. Due to personal differences, pupils have their own interest for different subjects, and math is a typical subject to demonstrate this phenomenon. A study of science subject preference shows that self matches better with favorite-subject prototype, subject preference will be stronger [16]. For instance, some pupils love math because math prototype fit in with them better than other subjects. 


\subsection{Teacher-pupil relations affect pupils' subject preference}

Primary school is an early stage of study. In this stage pupils are forming academic habits on subjects they are learning. Subject preference is included in them. Once the certain attitude towards a subject have been formed, it will be hard for them to alter in the later stages of studying, which shows the importance of factors that may influence pupils' preference in the early education [17]. The impact of teacher-pupil relations is one of the main factors that affect pupils' subject preference.

Pupils' motivation towards a certain subject forms their preference of it, and the development of motivation comes from their cognition of class atmosphere. Class atmosphere is established by both pupils and teachers. If a teacher has bad relations with pupils, the atmosphere of study will become worse, and soon affect pupils' attitude towards this subject taught by this teacher. Studies show that bad atmosphere in class between teachers and pupils can make motivation of pupils decrease [18].

Pupils of different genders have different subject preference, and they will establish different relations with their teachers. Girls and boys have showed differences not only in physical but also in personalities when being in the age of primary school. Donna M. Tuman has done a study of drawing about children of different genders [19]. He mentioned that when facing a drawing topic about "conflict", girls tended to imagine quarrels between family members, while boys thought "conflict" was about wars. In the end of the study, Tuman pointed out that when two groups are drawing, they would not jump out the predicted gender framework. That could prove the traditional traits of girls and boys: Girls tend to be quiet, sensitive and focus more on humanities. Boys are adventurous. When they meet troubles such as dealing with bad relations with their teachers, they will use methods to solve them which are dissimilar, due to their characteristics.

The discrepancy decides pupils' attitude towards teachers when relations are getting worse. The findings of Sue Walker et al. reveals girls are likely to have pro-social response when they are dealing with problems [20]. Boys are more aggressive and angry. Dodgeet al. said "Girls appear to participate in mitigate conflicts than boys" [21], which might prove that when being criticized on academic problems, there is a high probability that girls are quiet and listen to teachers. They try to avoid conflicts, while boys are likely to have quarrels with teachers. They may not be convinced that easily. Apart from the study of Sue Walker t al., Stake and Katz pointed out that girls tend to be more obedient than boys in class, and boys are noisier than girls [22]. The data also demonstrates that female teachers are more active to pupils' response than male teachers. Lack of social approval for male teachers makes them contain less passion towards pupils when teaching.

Pupils' gender may decide their ways of dealing with bad relations with teachers. Also, teachers' gender may let them choose different paths to educate pupils when academic problems appear. These will make difference on pupils' subject preference. If teachers deal with bad relations with pupils of dissimilar characteristics in an inappropriate way or without individualization, they are actually combating pupils' learning motivation. From teachers' perspective, establishing positive relations with pupils can inspire them to promote pupils achievement, and bad relations such as conflicts with pupils' will stop teachers from facilitating good atmosphere [23]. This explains why good and healthy relations will boost pupils' interest towards a certain subject, and bad relations will prevent them from having interest with it.

\section{CONCLUSION}

The finding of this study reveals that when teachers and students have conflicts or they do not reach to agreement, multiple elements might be injected into their relations: socio-demographic factors such as gender, personalities, learning atmosphere, parenting styles. For the discrepancy of different genders, the characteristics of boys and girls are dissimilar, and this will make their dealing with teachers under a bad situation have unlikeness in some aspects.

The future studies should focus more on what steps should be taken to restore bad teacher-pupil relations. The more teachers self-disclose to students, the more students will be interested in their curriculum [24]. Establishing certain teaching methods facing on different genders contributes to both teachers and pupils. Offering pupils right opportunities and methods to help promote their personal cognition and creative is a prior thing that teachers have to do in the teaching schedule. When communicate with boys and girls in elementary school, teachers ought to think about more before they take actions. Teachers themselves need to learn about features of pupils to understand the causes of their behavior, and optimize their teaching process. In the future, the effects that are brought by teacher-pupil relations to subject preference should be given more attention to by researchers.

\section{REFERENCES}

[1] Heath, C., \& Hindmarsh, J. (2002). Analysing interaction. Qualitative Research in Action, London: Sage, pp. 99-121.

[2] Naz, F., \& Murad, H. S. (2017). Innovative Teaching Has a Positive Impact on the Performance 
of Diverse Students. SAGE Open. https://doi.org/10.1177/2158244017734022

[3] Furrer C, Skinner E. Sense of relatedness as a factor in children's academic engagement and performance $[\mathrm{J}]$. Journal of educational psychology, 2003, $95(1): \quad 148 . \quad$ DOI: https://psycnet.apa.org/doi/10.1037/0022-0663.95.1 .148

[4] Rothstein, Jesse. 2017. "Measuring the Impacts of Teachers: Comment." American Economic Review, 107 (6): 1656-84.DOI: $10.1257 /$ aer.20141440

[5] S.R. St J. Neill (1989) The Effects of Facial Expression and Posture on Children's Reported Responses to Teacher Nonverbal Communication, British Educational Research Journal, 15:2, 195-204, DOI: 10.1080/0141192890 150207

[6] Mary L. Wolfe \& John D. Engel (1978) Dimensions of Opinion about Teacher-Pupil Relations, The Journal of Experimental

Education, 46:3, 41-45, DOI: 10.1080/00220973.19 78.11011630

[7] Murray Aitkin* \& Ruth Zuzovsky (1994) Multilevel Interaction Models and their Use in the Analysis of Large-scale School Effectiveness Studies, School Effectiveness and SchoolImprovement, 5:1, 45-73,

DOI: $10.1080 / 0924345940050104$

[8] Marsh, H. (2012). Relationships for learning: using pupil voice to define teacher-pupil relationships that enhance pupil engagement. Management in Education, 26(3),161163. https://doi.org/10.1177/0892020612445702

[9] Markus Talvio, Kirsti Lonka, Erkki Komulainen, Marjo Kuusela \& Taru Lintunen (2015) The development of teachers' responses to challenging situations during interaction training, Teacher Development, 19:1, 97-115, DOI: 10.1080/136645 30.2014.979298

[10] DePaulo B.M., Jordan A. (1982) Age Changes in Deceiving and Detecting Deceit. In: Feldman R.S. (eds) Development of Nonverbal Behavior in Children. Springer, New York, NY. DOI: https://doi.org/10.1007/978-1-4757-1761-7_6

[11] K. M. Evans (1959) THE TEACHER -- PUPIL RELATIONSHIP, Educational Research, 2:1, pp.3-8, DOI: 10.1080/00131885900 20101
[12]Shennum W.A., Bugental D.B. (1982) The Development of Control over Affective Expression in Nonverbal Behavior. In: Feldman R.S. (eds) Development of Nonverbal Behavior in Children. Springer, New York, NY. DOI: https://doi.org/10.1007/978-1-4757-1761-7_4

[13] Zivin G. (1982) Watching the Sands Shift: Conceptualizing Development of Nonverbal Mastery. In: Feldman R.S. (eds) Development of Nonverbal Behavior in Children. Springer, New York,NY. DOI: https://doi.org/10.1007/978-1-4757-1761-7_3

[14] MCNEILL, DAVID. "Iconic gestures of children and adults", vol. 62, no. 1-2, 1986, pp. 017-128 DOI: https://doi.org/10.1515/semi.1986.62.1-2.107

[15] J. Childs-Fegredo, A.-M. Burn, R. Duschinsky, A. Humphrey, T. Ford, P. B. Jones, E. Howarth, Acceptability and Feasibility of Early Identification of Mental Health Difficulties in Primary Schools: A Qualitative Exploration of UK School Staff and Parents' Perceptions, School Mental Health, DOI: 10.1007/s12310-020-09398-3, (2020).

[16] Bettina Hannover, Ursula Kessels, Self-to-prototype matching as a strategy for making academic choices. Why high school students do not like math and science, Learning and Instruction, Volume 14, Issue 1, 2004, pp. 51-67, ISSN 0959-4752, DOI: https://doi.org/10.1016/j.learninstruc.2003.10.002

[17] Sanders, W. L., \& Rivers, J. C. (1996). Cumulative and residual effects of teachers on future student academic achievement.

[18] Maulana R, Opdenakker M C, Bosker R. Teacherstudent interpersonal relationships do change and affect academic motivation: A multilevel growth curve modelling $[\mathrm{J}]$. British journal of educational psychology, 2014, 84(3): 459-482.

[19] Donna M. Tuman (1999) Gender Style as Form and Content: An Examination of Gender Stereotypes in the Subject Preference of Children's Drawing, Studies in Art Education, 41:1, pp. 40-60, DOI: 10.1080/00393541.1999.11651664

[20] Sue Walker, Kym Irving \& Donna Berthelsen (2002) Gender Influences on Preschool Children's Social Problem-Solving Strategies, The Journal of Genetic Psychology, 163:2, pp. 197-209, DOI: 10.1080/00221320209598677

[21] Stake JE, Katz JF. Teacher-Pupil Relationships in the Elementary School Classroom: Teacher-Gender and Pupil-Gender Differences. American 
Educational Research Journal. 1982; pp. 19(3):465-471. DOI:10.3102/00028312019003465

[22] Hamre B K, Pianta R C. Early teacher-child relationships and the trajectory of children's school outcomes through eighth grade[J]. Child development, 2001, pp.72(2): 625-638.

[23] Cayanus, J. L., Martin, M. M., \& Weber, K. (2003, April). The relationships between teacher selfdisclosure with out-of-class communication, student interest, and cognitive learning. Paper presented at the Southern States Communication Association Convention, Birmingham, AL. 